\title{
Determinantes dos Preços de Terras no Brasil: uma análise de região de fronteira agrícola e áreas tradicionais
}

\author{
Aline Barrozo Ferro $^{1}$ e Eduardo Rodrigues de Castro $^{2}$
}

\begin{abstract}
Resumo: $\mathrm{O}$ estudo tem como objetivo analisar o impacto de variáveis sobre o preço da terra agrícola entre 2000 e 2010 em três regiões: fronteira agrícola (sul do Maranhão, sul do Piauí, leste do Tocantins e oeste da Bahia), área de transição (exploração relativamente recente, mas representa um importante produtor de soja, como o Centro-Oeste) e desenvolvida (áreas tradicionais, como o Sul do País). Foram utilizadas as variáveis preço de soja, produtividade, área cultivada, crédito rural, investimento em transporte, capacidade de armazenamento e preço da terra no período anterior. A partir do modelo econométrico de dados em painel, observou-se que o preço da soja (representando a renda do produtor), teve relação estreita e positiva com o preço da terra. Verificou-se, também, que nas regiões menos ocupadas um aumento da demanda por área pode impactar negativamente em seu preço devido à maior elasticidade da oferta de terras e à possibilidade de conversão de terras brutas e de pastagens em agrícolas. Já na região desenvolvida, a relação é positiva, já que a oferta de terras é praticamente inelástica. $\mathrm{O}$ fator especulativo foi bastante representativo na fronteira agrícola, o que evidenciou o forte interesse de investidores no potencial de valorização da terra no período.
\end{abstract}

Palavras-chaves: Mercado de terra, fronteira agrícola, dados em painel.

Abstract: The objective of this research is to analyze the impact of variables in the agricultural land price formation between 2000 and 2010 in three different regions in Brazil: the most recent agricultural frontier (southern Maranhão, southern Piaui, southeastern Tocantins and western Bahia), the transition area (which has a relatively recent exploration, but the agricultural exploitation has already been established, such as the Central-Western region in Brazil) and the traditional area (with established agricultural activities, as the Southern). The variables used were soybean price, productivity, cultivated area, rural credit, investments in transportation, capacity of storage and land price in previous periods. The analysis is carried out with a panel data model, and it was observed

1 Mestre em Economia pela Universidade Federal de São Carlos (UFSCar) e Engenheira Agrônoma pela Escola Superior de Agricultura "Luiz de Queiroz" - Esalq/USP. E-mail: abferro@gmail.com

2 Professor Adjunto do Departamento de Economia da Universidade Federal de São Carlos, Campus Sorocaba. E-mail: eduardo@ufscar.br 
that soybean price, which represents land revenue, has the major influence in the land price. In the agricultural and transition areas, increases in land demand have negative impact in the land price, due to the increase in the land supply. On the other hand, in the traditional area, increases in the demand push up the land price, due to the inelastic land supply. The speculation variable was not important in the transition and traditional areas, but it has an important contribution to land prices formation in the agricultural frontier.

Key-words: Land market, agricultural frontier, panel data.

Classificação JEL: Q11, Q15, Q24.

\section{Introdução}

O Brasil tem se mostrado como uma das principais alternativas para o aumento da produção de alimentos e energia. Além disso, tem sido alvo de investimentos estrangeiros para aquisição e arrendamento de terras com o intuito de produzir alimentos, para fins especulativos ou ambos. As novas áreas de fronteira agrícola no Brasil que têm sido o principal foco dos investimentos localizam-se principalmente no Norte e Nordeste. Estas áreas são ainda pouco exploradas e, consequentemente, têm elevado potencial de valorização na medida em que há aumento de sua ocupação e desenvolvimento da infraestrutura, podendo gerar lucro aos investidores no longo prazo. Desta forma, evidencia-se a seguinte questão: como alguns dos fatores que determinam o preço da terra impactam em áreas de fronteiras agrícolas e tradicionais?

De acordo com Sicsú e Lima (2000), o potencial de valorização do capital na fronteira, via produção efetiva ou via especulação, está diretamente relacionado à expansão da infraestrutura de transportes e comunicações, além de incentivos fiscais e creditícios, entre outros. Miranda e Gomes (2011) avaliam ainda que, na região de fronteira agrícola conhecida como Mapito (que abrange o sul do Maranhão e do Piauí e o leste do Tocantins), alguns dos fatores que impulsionaram o desenvolvimento agrícola foram os estímulos governamentais, como oferta de crédito, pesquisa e assistência técnica e, numa segunda fase, a profissionalização do processo produtivo de grãos, com a instalação de empresas nacionais e internacionais. Desta forma, espera-se que os produtores que se estabelecem primeiro em uma região de fronteira, apesar da menor oferta de infraestrutura, têm ainda o potencial de ganho com a valorização da terra.

A fronteira agrícola atual apresenta um padrão de ocupação semelhante ao do CentroOeste, que se caracteriza pelo predomínio de grandes produtores. Rezende (2001) observou que os agricultores locais estruturaram suas bases independentemente da política de crédito rural, e a região acabou concentrando uma presença relativamente maior de produtores capitalizados. Rezende (2003) explica que o rigor climático torna a agricultura familiar inviável nessas regiões, já que não é capaz de obter renda no período seco do ano, além de tornar menos viável o desenvolvimento de outras atividades além de grãos e pecuária (pelo fato de utilizarem intensivamente 
a terra, o fator mais barato que a região possui). Assim, o custo de oportunidade da terra usada nas atividades de grãos e pecuária seria praticamente nulo, aumentando a competitividade nessas regiões comparativamente a outras. A produção em grande escala no Cerrado torna-se mais competitiva com a possibilidade de mecanização, reduzindo os custos de preparo da terra, e com o preço mais baixo deste fator na região (REZENDE, 2003).

Castro e Fonseca (1994) argumentam, ainda, que a diferença dos valores da terra nas diversas regiões é dada também pelo preço recebido pelo produtor - dado que refletem a renda obtida pela terra - devido à distância aos principais centros consumidores. Entretanto, segundo os autores, algumas empresas acreditam que a proximidade com a área produtora traz vantagens competitivas de localização, o que permite reduzir custos de transporte de cargas entre a planta industrial e a zona de cultivo, mesmo havendo problemas no transporte do produto para o resto do País.

De acordo com Rezende (2003), a inovação tecnológica também foi um fator de elevada importância neste cenário, visto que o menor preço da terra também está associado ao contínuo aumento do estoque de terra de boa qualidade, por meio da conversão de terras agricultáveis de qualidade inferior e de terras virgens. A nova tecnologia é importante não somente pela redução no custo de conversão, mas também pela possibilidade desta conversão.

A produtividade agrícola foi apontada por Castro e Fonseca (1994) como fator de extrema relevância na valorização das áreas de fronteira, e uma das principais atratividades dessas regiões, dado que esses ganhos estão relacionados ao potencial ainda não esgotado de modernização agrícola da região, e não apenas à expansão horizontal, que é caracterizada pelo aumento da área de cultivo. O aumento da produtividade que possibilita ganhos de rentabilidade - atrai não somente agricultores, como grandes indústrias para a região do Cerrado. Assim, conforme apontado por Castro e Fonseca (1994), tende a se estabelecer na fronteira um perfil de agroindús- tria cujos investimentos acabam sendo complementares entre si. Entre os setores mais capazes de induzir investimentos do setor agrícola estão o de óleo vegetal em bruto e o de abate de carnes (PRADO, s/d. apud CASTRO e FONSECA, 1994). Os dois segmentos provocam um encadeamento com a base produtiva agropecuária, indústrias de insumos e máquinas agrícolas, comercialização e transporte.

Para ilustrar a diferença no comportamento de preços da terra, a média de preços das áreas desenvolvidas, segundo cotações do Agrianual, da consultoria AgraFNP, representou, em 2002, mais de cinco vezes o preço médio da terra de fronteira, enquanto o preço da terra em fase de transição foi 2,6 vezes maior ${ }^{3}$. Em 2010, essa relação caiu para 3 no caso da terra desenvolvida e 1,5 para região de transição. Isso mostra que a evolução do preço da terra de fronteira foi maior neste período (entre 2002 e 2010) em relação às demais regiões. Enquanto o crescimento médio anual do preço da terra foi de $6 \%$ nas áreas desenvolvidas e em transição (já considerando o efeito da inflação), o acréscimo foi de $13 \%$ a.a. na fronteira agrícola, o que evidencia o potencial de valorização desta região. A valorização da terra em áreas de fronteira agrícola foi mais expressiva entre 2007 e 2008, justamente quando houve uma maior demanda por terra por parte dos novos grupos de investimentos. Desta forma, o impulso nas cotações naquele período foi maior na fronteira agrícola frente às demais regiões, evidenciando seu potencial de crescimento.

Diversos trabalhos procuraram identificar os determinantes de preços da terra no Brasil. Sayad (1977) considerou a terra como reserva de valor, mostrando que fatores relacionados à macroeconomia teriam maior influência sobre o preço da terra; Oliveira e Costa (1977) avaliaram, ainda, que variáveis relacionadas à renda de produtores e infraestrutura tinham relação positiva com o preço da terra; Pinheiro (1980) mostrou que a evolução de preços da terra entre 1966 e 1978 estava

\footnotetext{
3 Para análise de preços de terras por região, foram consideradas as divisões das mesmas descritas na metodologia.
} 
associada ao período conhecido como "milagre econômico"; Rezende (1985) afirmou que um aumento da capacidade financeira de agricultores estimula fortemente a aplicação de capital na agricultura. Egler (1985) concluiu que a simples presença da taxa de juros negativa já explicaria a valorização da terra, pois bastaria que a terra tivesse uma renda positiva para que seu preço estivesse em constante aceleração; para Brandão (1988), a demanda por terra para fins agrícolas depende dos preços dos produtos agrícolas em relação aos preços dos insumos, da taxa de juros real do crédito rural, do avanço tecnológico e do preço real de insumos modernos. Bacha (1989), conclui que as variáveis vinculadas à produção agropecuária exerceram maior influência sobre o preço da terra do que as vinculadas à especulação e ao ambiente econômico. Reydon e Plata (1998) concluíram que, no período de 1966 a 1975, o crescimento do preço da terra foi influenciado pela modernização da agricultura associada a um conjunto de inovações tecnológicas, que incrementaram a produtividade, provocando aumento no preço da terra. Assim, alguns fatores potencializaram as expectativas de ganhos produtivos e especulativos com o uso da terra, como a maior demanda por terras devido à necessidade de escalas de produção.

Rahal (2003) observa grande sensibilidade dos preços da terra frente à atividade agrícola na determinação dos preços da terra em detrimento a variáveis macroeconômicas e crédito rural. Entretanto, o trabalho mostra relativa importância de variáveis indiretamente ligadas à atividade, como taxa de inflação, taxa de juro e hiato do produto. Para Barros (2009), o preço da terra apresenta relação positiva com a área de cultivo (dada uma relação de demanda) e negativa com a produtividade, tendo em vista que um aumento da produtividade reduz a demanda por terra e favorece queda de preços. A partir de 2000, a produtividade se estabiliza ou reduz e o aumento da produção agrícola passaria a depender da expansão da área de cultivo, favorecendo a valorização da terra.

O objetivo deste trabalho é identificar as diferenças de comportamento do mercado de terra nas regiões de fronteira agrícola, de transição e desenvolvida por meio da análise do impacto de algumas variáveis sobre o preço deste fator. Com base na literatura, procurou-se observar a influência de alguns fatores que pudessem diferenciar as três regiões, como o nível de infraestrutura, a necessidade de crédito agrícola, área agrícola disponível e o fator especulativo. Além disso, foram analisadas variáveis relacionadas à renda obtida com a terra, como preço de soja e produtividade, tendo em vista a importância dada a este item na teoria econômica. O período analisado (2002 a 2010), embora seja relativamente curto em função da disponibilidade dos dados, abrange uma fase de grande destaque no mercado de terras na fronteira agrícola, pois capta a crescente valorização das terras num período em que ocorreu uma elevada expansão da demanda por este fator por parte de investidores. Neste cenário, torna-se necessária uma análise comparativa entre a região, que vem ganhando destaque na produção de soja no Brasil, com outros polos mais tradicionais na produção de grãos.

O estudo está dividido em quatro seções, além da introdução. A seção a seguir apresenta breve revisão de literatura que aborda a teoria sobre os determinantes do preço da terra; em seguida, é apresentada a metodologia utilizada, as razões para a escolha do modelo econométrico, os testes realizados e as variáveis escolhidas; o quarto capítulo trata dos resultados obtidos e da discussão sobre os mesmos; por fim, é apresentada a conclusão do trabalho.

\section{Revisão de literatura}

A literatura mostra que os primeiros estudos sobre o mercado de terras derivam das teorias que associam o valor da terra à sua capacidade de gerar renda. Dentro da teoria clássica, em 1815 , surgiram quatro publicações elaboradas por West, Torrens, Malthus e Ricardo que apresentaram a teoria conhecida como "teoria da renda diferencial", formalizada de forma mais abrangente por Ricardo (PINHEIRO, 1980). 
As escolas neoclássica e marxista partem de premissas que tendem a fazer a associação do preço da terra à renda por ela gerada: os neoclássicos colocam o preço da terra determinado pela produtividade marginal do fator, enquanto os marxistas consideram a renda que esta terra poderia gerar, capitalizada pela taxa de juros da economia (REYDON, 1992).

A partir de 1950 houve uma tendência inesperada de elevação do preço da terra nos Estados Unidos acima dos ganhos produtivos, o que ficou conhecido como o "paradoxo do preço da terra". Desta forma, constatou-se que outros fatores, além dos produtivos, poderiam determinar o preço da terra. Houve, então, a necessidade de se buscar referências principalmente nos estudos do mercado financeiro e dos ativos econômicos para explicar a questão do mercado de terras.

Scofield (1957) e, posteriormente Chryst (1965), avaliaram o "paradoxo do preço da terra". O motivo mais óbvio para este fato, segundo Scofield (1957), era a diminuição do poder de compra da moeda, o que levou à retenção da propriedade e elevou a demanda pelo bem - a terra tbornara-se uma excelente proteção contra a perda do poder de compra, ou seja, serviria de reserva de valor. Outro fator seria a expectativa de aumento da população, que necessitaria de mais alimentos e demandaria mais terra. $\mathrm{O}$ autor observa que, além de fatores produtivos, o mercado de terras está fortemente associado a elementos relacionados à tradição, valores sociais e crenças, e mudam constantemente entre diferentes grupos. Estes fatores não são mesuráveis, e acabam sendo excluídos das análises. O mercado de terras é sensível à política econômica nacional e às mudanças que podem ser previstas. Se o governo federal se compromete a manter e elevar o nível da atividade econômica, as pessoas têm maior confiança e podem investir com mais segurança (SCOFIELD, 1957).

Herdt e Cochrane (1966) observaram que as discussões sobre preços de terra estavam centradas na demanda por este fator, o que indicaria que a oferta de terras não tem efeito sobre seu preço. Além disso, assumir que a oferta é comple- tamente inelástica não seria aceitável. Os autores consideraram que os preços de terra são determinados no mercado pela interação entre forças de oferta e de demanda. De acordo com estes autores, outra variável que influencia a demanda por terras é o nível geral de preços dos produtos, além da relação do índice de preços recebidos pelos produtores e do índice de preços pagos, que reflete a rentabilidade obtida com a terra. Um incremento dessa relação aumentaria a expectativa de renda da terra, o que aumentaria a demanda pelo fator. A política de suporte de preços tenderia a aumentar a relação entre preços recebidos e preços pagos pelos produtores, elevando, dessa forma, a expectativa de renda. Neste sentido, o avanço tecnológico também teria o papel de aumentar a renda através da redução dos custos de produção, incentivando a expansão produtiva e elevando a demanda por terra.

Reinsel e Reinsel (1979) assumiram que o valor presente da terra seria a principal ferramenta para formar o preço deste fator. Ou autores utilizaram a seguinte fórmula:

$$
V=\sum \frac{a_{t}}{\left(1+i_{t}\right)^{t}}
$$

em que $V$ é o valor corrente do ativo, é o valor esperado do retorno no ano $t$, e $i$ é o valor esperado da taxa de desconto no ano $t$. Segundo os autores, em determinado ano, o retorno esperado é função dos preços das commodities agrícolas e de insumos, produtividade, inflação, taxa de juros, crédito, entre outras variáveis. Reinsel e Reinsel (1979) avaliam principalmente fatores relacionados à expectativa de ganhos, que afetam a demanda por terra; para eles, o mais relevante seria o crescimento populacional. Os autores consideram a oferta de terras fixa, assim, a valorização da terra será resultado de aumento da demanda por alimento, fibras e espaço.

Rezende (1982), analisando a relação entre preços da terra no Brasil e ciclo econômico, constatou que, na década de 1970, houve elevação dos preços da terra num ritmo muito superior ao aumento do preço do arrendamento. Isso indicou que as vantagens associadas à posse da terra 
como um ativo superavam aquelas advindas da atividade agrícola. Considera-se a seguinte fórmula simplificada de formação de preço da terra:

$$
T=\frac{1}{r} * R
$$

em que $T$ é preço da terra; $R$ é o rendimento derivado da posse da terra e $r$ equivale aos demais retornos da economia. $\mathrm{O}$ autor justifica que, dado um rendimento de posse da terra mais estável ciclicamente em relação aos demais retornos da economia, haveria uma modificação no portfólio de investidores, com aumento da demanda da terra e elevação de seu preço relativamente ao valor de aluguel. Para ele, a maior estabilidade relativa da renda da terra, no ciclo econômico, explica o fato de a terra possuir e servir de "reserva de valor" na economia.

\section{Metodologia}

Neste trabalho, procurou-se determinar o impacto de variáveis mais relacionadas com a produção agrícola e com as expectativas. Desta forma, foi utilizado o modelo de dados em painel, em que se combinam dados de séries temporais e de "cross-section", possibilitando um aumento do número de graus de liberdade e diminuição da colinearidade entre as variáveis explicativas. Além disso, o modelo permite mensurar efeitos que não são possíveis de serem captados individualmente por meio da análise de séries temporais ou de "cross-section".

As regiões analisadas, que representam as unidades do modelo de dados em painel, possuem características distintas, como grau de ocupação agrícola, desenvolvimento, aspectos culturais, entre outras, que influenciam o preço da terra (variável dependente), mas não são possíveis de serem observadas. A omissão dessas variáveis pode gerar resultados viesados (DUARTE, LAMOUNIER e TAKAMATSU, 2007), sendo necessário captar esses efeitos, o que poderia ser feito por meio da introdução de variáveis de controle. No entanto, uma das vantagens do modelo de dados em painel é que esse método controla a heterogeneidade presente nas unidades, isolando efeitos específicos, permitindo controlar as diferenças existentes entre as regiões (HSIAO, 2003).

Considerando-se todas as unidades, o modelo é expresso da seguinte forma (WOODRIDGE, 2001):

$$
y_{i t}=\beta_{k} \cdot X_{i t}+v_{i t}
$$

em que cada variável constitui-se das observações temporais de cada unidade, dispostos em sequência. A variável $y_{i t}$ representa o preço da terra da seção cruzada $i$ no período $t$; $\beta$ são os parâmetros a serem estimados; $X_{i t}$, as variáveis independentes, que serão especificadas mais adiante; $v_{i t}$ é o termo de erro aleatório.

Em sua forma mais simples, o modelo não faz distinção entre o intercepto das diferentes unidades e nem em relação à estrutura do termo de erro aleatório. No entanto, considerando-se várias seções cruzadas, é possível que existam diferenças entre as unidades que não são observáveis $\left(c_{i}\right)$ e que não variam ao longo do tempo. Para se captar os efeitos não observáveis existem duas alternativa s, o modelo de Efeitos Fixos e o modelo de Efeitos Aleatórios. De acordo com Woodridge (2001), a diferença entre as duas especificações está no fato de os efeitos não observáveis estarem ou não correlacionados com as variáveis observáveis presentes em $X_{i t}$. Se o termo $c_{i}$ é correlacionado com $X_{i t}$, o modelo de efeitos fixos é mais apropriado e permite captar as diferenças de intercepto para as diferentes unidades.

\subsection{Modelo de efeitos fixos}

O modelo de efeitos fixos controla os efeitos das variáveis omitidas, captados pelo intercepto, que variam entre os indivíduos e permanecem constantes ao longo do tempo. Os parâmetros resposta são constantes para todos os indivíduos e ao longo do tempo. Assim, todas as diferenças de comportamento dos indivíduos serão captadas pelo intercepto. Vale ressaltar que as inferências acerca do modelo são somente sobre os 
indivíduos da amostra (DUARTE, LAMOUNIER e TAKAMATSU, 2007).

Para uma unidade específica, o modelo pode ser especificado da seguinte forma, segundo Woodridge (2001):

$$
y_{i}=\beta_{k} \cdot X_{i}+c_{i} j_{T}+v_{i}
$$

em que $c_{i}$ é o intercepto do modelo de efeitos fixos que capta a diferença entre as unidades (não varia com o tempo) e $j_{T}$ é um vetor unitário $T \times 1$.

De uma forma mais simplificada, Duarte, Lamounier e Takamatsu (2007) explicam a equação do modelo de efeitos fixos utilizando variáveis binárias proposta por Stock e Watson (2004) da seguinte forma:

$$
\begin{aligned}
& y_{i t}=\beta_{0}+\beta_{1} x_{1 i t}+\ldots+\beta_{k} x_{k i t}+\gamma_{2} D_{2 i}+\gamma_{3} D_{3 i}+\ldots+ \\
& +\gamma_{n} D_{n i}+e_{i t}
\end{aligned}
$$

em que $D_{n i}$ representa uma variável binária para cada indivíduo e equivale a 1 quando $i=n$ e a zero caso contrário. Omite-se uma variável binária para que não haja problema de multicolinearidade. Neste modelo, $\beta_{0}, \beta_{1}, \ldots, \beta_{k}, \gamma_{2}, \ldots, \gamma_{n}$ são os parâmetros a serem estimados; quando $i=1$, o intercepto é dado por $\beta_{0}$ (equivalente a $c$ ). Para $i \geq 2$, o intercepto é dado por $\beta_{0}+\gamma_{i}$.

Gujarati e Porter (2011) advertem que um dos possíveis problemas relacionados a este modelo é que, em algumas situações, o modelo de efeitos fixos pode não ser capaz de identificar o impacto de variáveis do tipo "cross-section". Em outras palavras, os interceptos específicos a um sujeito absorveriam a heterogeneidade existente nas variáveis dependente e explanatória.

\subsection{Modelo de efeitos aleatórios}

No modelo de efeitos aleatórios, o intercepto também varia de um indivíduo para outro e não ao longo do tempo. Além disso, os parâmetros resposta também são constantes para todos os indivíduos e em todos os períodos de tempo. Desta forma, a diferença em relação aos efeitos fixos está no intercepto, que é tratado como variável aleatória. Ou seja, o modelo con- sidera que os indivíduos são uma amostra aleatória de uma população de indivíduos (DUARTE, LAMOUNIER e TAKAMATSU, 2007). O modelo geral, segundo Wooldridge (2001), é dado por:

$$
y_{i t}=x_{i t} \beta+v_{i t}
$$

Neste caso, a variável não observável não é correlacionada com as variáveis em $X_{i t}$, e o termo $c_{i}$ pode constar no termo de erro aleatório, que assume a forma:

$$
v_{i t}=u_{i t}+c_{i}
$$

O modelo de efeitos aleatórios não capta as diferenças existentes entre as unidades por meio do intercepto. Apesar disso, é possível estimar a participação dos efeitos não observáveis $\left(c_{i}\right)$ no termo de erro aleatório.

De acordo com Gujarati e Porter (2011), o modelo de efeitos aleatórios é estimado por meio dos Mínimos Quadrados Generalizados (MQG). Isso ocorre porque uma das propriedades do modelo é que há presença de correlação entre os termos de erro, o que inviabiliza a aplicação do método de Mínimos Quadrados Ordinários (MQO).

Para se definir qual modelo é o mais apropriado, ambas as formas são estimadas e testadas, verificando-se qual especificação melhor se adapta aos dados. Para isso, é utilizado o Teste de Hausman, como será visto adiante.

Foram utilizados três grupos de dados, formando, portanto, três modelos de dados em painel, assim divididos: grupo de áreas de fronteira agrícola, grupo de áreas em transição e grupo de áreas desenvolvidas.

\subsection{Testes Econométricos}

O modelo de dados em painel considera várias equações; portanto, é necessário verificar a existência de correlação contemporânea nos termos de erro das diferentes equações. Segundo Judge et al. (1988), quando há presença de correlação contemporânea, estimar todas as equações conjuntamente (estimação conhecida 
como "Seemingly Unrelated Regressions", ou SUR) pode ser mais eficiente do que estimar as equações separadamente pelo método de Mínimos Quadrados Ordinários.

Quando não existe correlação contemporânea, o método de Mínimos Quadrados Ordinários (MQO) aplicado ao conjunto de equações não traz ganhos adicionais se comparado à aplicação em cada equação separadamente. Assim, é necessário analisar se há ausência de correlação contemporânea para saber qual método é o mais adequado. A estatística apropriada é o Teste de Lagrange, sugerido por Breusch e Pagan (1980, citados por JUDGE et al., 1988):

$$
\lambda=T\left(r_{21}^{2}+r_{31}^{2}+r_{32}^{2}\right)
$$

em que $r_{i j}^{2}$ representa o quadrado da correlação dos resíduos:

$$
r_{i j}^{2}=\frac{\hat{\sigma}_{i j}^{2}}{\hat{\sigma}_{i i} \hat{\sigma}_{j j}}
$$

Sob a hipótese nula, $\lambda$ tem distribuição assintótica $X^{2}$. No caso geral de equações, a estatística é dada por:

$$
\lambda=T \sum_{i=2}^{M} \sum_{j=1}^{i-1} r_{i j}^{2} \Rightarrow \lambda \sim X^{2}
$$

em que $M$ representa o número de equações e $T$ representa tamanho da amostra.

Se $\lambda<X^{2}$, a hipótese nula não é rejeitada e, portanto, há ausência de correlação contemporânea. Neste caso, o modelo poderia ser estimado pelo método MQO. Se $\lambda>X^{2}$, rejeita-se a hipótese nula indicando, portanto, presença de correlação contemporânea. Assim, deve ser aplicado o SUR, MQG ou outros métodos de estimação.

O teste de correlação contemporânea foi feito para os todos os modelos abordados neste trabalho, e os resultados serão apresentados ao longo da discussão dos resultados.

O Teste de Hausman é utilizado para verificar qual o modelo mais adequado, de efeitos fixos ou aleatórios. A hipótese nula é que os estimadores do modelo de efeito fixo e do modelo de efeitos aleatórios não diferem substancialmente. $\mathrm{O}$ teste estatístico tem uma distribuição assintótica $X^{2}$; se a hipótese nula for rejeitada, a conclusão é que o modelo de efeitos aleatórios não é adequado, pois os efeitos aleatórios provavelmente estão correlacionados com um ou mais regressores (GUJARATI e PORTER, 2011).

O principal determinante para a escolha é o efeito não observável $\alpha_{i}$. A estatística do teste de Hausman, conforme apresentado em Wooldrigde (2001), é dada por:

$$
H=\left(\hat{\delta}_{E F}-\hat{\delta}_{E A}\right)\left[A v \hat{a} r\left(\hat{\delta}_{E F}\right)-A v \hat{a} r\left(\hat{\delta}_{E A}\right)\right]^{-1}\left(\hat{\delta}_{E F}-\hat{\delta}_{E A}\right) \sim \chi_{K}^{2}
$$

em que $\hat{\delta}_{E F}$ é o vetor dos estimadores de efeitos fixos; $\hat{\delta}_{E A}$ é o vetor dos estimadores do modelo de efeitos aleatórios; Avâr é a matriz de variâncias-covariâncias dos respectivos estimadores e $k$ é o número de regressores. Desta forma, a hipótese nula é de que $\alpha_{i}$ não é correlacionado com as variáveis explicativas. Quando $\alpha_{i}$ é correlacionado com algumas variáveis explicativas, o modelo mais adequado é o de efeitos fixos.

\subsection{Variáveis utilizadas nos modelos}

Para a análise do mercado regional, o principal fator limitante para estimar os modelos desejados são os preços de terras. Isso ocorre porque a consultoria AgraFNP é a única fonte com uma série histórica de preços de terra por microrregião, e de forma mais abrangente, por todo o Brasil. O levantamento de preços, divulgado apenas a partir de 2002, divide as cotações por tipo de terra existente em cada região, de acordo com suas características e atividade agropecuária predominante, como será visto adiante.

Tomando-se como base a divisão de regiões da metodologia da AgraFNP, foram agrupados os dados de área de cultivo de soja por município, divulgada pela Pesquisa Agrícola Municipal, do IBGE (Instituto Brasileiro de Geografia e Estatística), obtendo-se as maiores regiões produtoras do grão. Da mesma forma, para a análise regional, todas as variáveis foram obtidas pelo agrupamento de dados municipais de acordo com a divisão das regiões estudadas pela consultoria AgraFNP. 
Outro ponto importante para escolha de regióes foi a disponibilidade de informações de um mesmo tipo de terra. Isso ocorreu porque existe uma grande heterogeneidade nos dados deste mercado. Para homogeneizar ao máximo as informações deste estudo, tendo em vista que o foco foi analisar as diferenças em polos produtores de soja, buscou-se utilizar os dados em áreas que possuíam preços de terra para lavoura.

No caso do grupo de regiões de fronteira agrícola, em função da menor quantidade de informações, foram abordadas todas as regiões que possuíam preços de terra agrícola (sete no total).

Desta forma, foram abordadas as seguintes regiões:

a) Grupo de regiões de fronteira agrícola: Balsas (MA), Codó (MA), Araguaína (TO), Gurupi (TO), Palmas (TO), Uruçuí (PI) e Oeste Baiano (BA).

b) Grupo de regiões desenvolvidas: Passo Fundo (RS), Uruguaiana (RS), Cascavel (PR), Campo Mourão (PR), Ponta Grossa (PR), Londrina (PR) e Guarapuava (PR).

c) Grupo de regiões em transição: Sinop(MT), Tangará da Serra (MT), Rondonópolis (MT), Barra do Garças (MT), Rio Verde (GO), Dourados (MS) e Rio Brilhante (MS).

O período de análise é de 2002 (início da série) a 2010, tendo em vista a limitação de dados disponíveis de preços de terras por região. Todos os dados foram transformados em logaritmo natural. Desta forma, os resultados obtidos já representam as elasticidades dos fatores em relação ao preço da terra. As séries de preços ou valores de crédito rural foram deflacionadas pelo Índice Geral de Preços - Disponibilidade Interna (IGP-DI), obtido junto ao Instituto de Pesquisa Econômica Aplicada (Ipea).

As variáveis são descritas a seguir:

PT $=$ Preço da terra agrícola. Tendo em vista a heterogeneidade desse fator em cada região, procurou-se utilizar o tipo de terra mais relacionado ao cultivo de soja. Em regiões que possuíam mais de uma categoria para preço de terra agrícola, como "terra de boa produtividade", "terra agrícola" ou "terra agrícola para grãos", foi feita a média aritmética entre os preços da região. Não foram incluídos preços de terras de baixa produtividade quando esta categoria existia, com o objetivo de analisar o mesmo tipo de terra - neste caso, as terras de melhor qualidade para produção de grãos, sem a necessidade de grandes investimentos para transformá-la em terras de qualidade superior. A média entre preços de terra de alta produtividade e de baixa poderia ainda causar um viés nos preços das áreas que são efetivamente utilizadas para o plantio de soja. Os dados referem-se à terra nua, ou seja, desconsidera as benfeitorias existentes nas propriedades rurais.

A fonte desses dados é o Agrianual, uma publicação da AgraFNP, que divulga preços de terras bimestralmente. No caso do estudo envolvendo as regiões, foram calculadas as médias anuais publicadas pela consultoria. Para os estados, a consultoria publica a média apenas de um bimestre do ano, geralmente julho/agosto. Foram utilizados estes dados disponíveis para considerar a evolução anual de preços da terra por estado.

$\mathbf{P R}=$ Produtividade média obtida com a soja, em sacas por hectare. Os dados foram obtidos por meio da divisão da quantidade produzida pela área plantada, da Pesquisa Agrícola Municipal, do IBGE. Foram considerados dados por municípios e agrupados nas regiões, conforme a divisão da pesquisa da AgraFNP. No caso do estudo por estado, foi considerada a média geral do estado.

PS = Preço obtido pela soja. Foram calculados os preços por saca de soja por meio da divisão do valor da produção pela quantidade produzida (dados da Pesquisa Agrícola Municipal, do IBGE). Calculou-se a média de preço de cada região, conforme os dados municipais. No caso dos dados estaduais, foram obtidas as médias gerais.

AC $=$ Área cultivada total, refere-se aos dados de área cultivada com lavoura permanente e temporária, segundo a Pesquisa Agrícola Municipal, do IBGE. Os dados foram obtidos por município e agrupados conforme as regiões da AgraFNP. No caso da pesquisa estadual, foram consideradas as áreas totais de cada estado. A escolha da área 
agrícola total deve-se ao fato de que esta variável captaria melhor a demanda geral por terras, seja para o cultivo de soja ou demais culturas que concorram pela área.

CRC $=$ Volume de crédito agrícola para custeio, coletado junto ao Anuário Estatístico do Crédito Rural, do Banco Central do Brasil. Foram obtidos dados por município e agrupados conforme a divisão de regiões da AgraFNP. Para os estados, foram considerados os volumes totais de crédito agrícola para custeio.

O volume de crédito agrícola para custeio representou, em média, durante todo o período analisado, $60 \%$ do total do crédito concedido à agricultura, que envolve também investimento e crédito para comercialização.

ARM = Capacidade de armazenamento de grãos. Os dados de capacidade estática dos armazéns graneleiros foram obtidos junto à Conab (Companhia Nacional de Abastecimento). A evolução desta variável, de 2002 a 2010, foi obtida apenas para os estados brasileiros, sendo assim considerada apenas no modelo referente aos estados.

No caso das informações regionais, os dados foram obtidos apenas para o ano de 2009. Entretanto, o teste desta variável (cross section) no modelo apresentou um erro em função da não variação ao longo do tempo, e não pode ser utilizada na análise regional. Vale ressaltar que a ocorrência desse tipo de erro foi inclusive citada por Gujarati e Porter (2011) como eventualmente possível em modelos de dados em painel.

INT = Investimento no setor de transportes (rodoviário, ferroviário, aquaviário, setor da marinha mercante, setor de transportes urbanos, entre outros), obtido junto ao Ministério dos Transportes. A variável refere-se ao investimento geral no Brasil, entre 2002 e 2010, não variando, portanto, entre as regiões. A mesma variável foi utilizada nos modelos regionais e estaduais.

Além disso, foi analisada em todos os modelos a variável $P T_{-1}$, que se refere ao preço real da terra no período anterior. O objetivo foi identificar se movimentos passados ajudariam a explicar o preço da terra atual, o que representaria as expectativas dos agentes sobre este mercado.

\section{Resultados e discussão}

A Tabela 1 mostra os resultados obtidos para cada grupo de regiões. Ressalta-se que todos os dados foram estimados na forma logarítmica e, portanto, os coeficientes obtidos representam as elasticidades.

Tabela 1. Coeficientes estimados e níveis de significância para o modelo de demanda de terras nas regiões de fronteira agrícola, de transição e desenvolvida (2002-2010)

\begin{tabular}{|c|c|c|c|c|c|c|c|c|c|}
\hline & \multicolumn{3}{|c|}{ Fronteira } & \multicolumn{3}{|c|}{ Transição } & \multicolumn{3}{|c|}{ Desenvolvida } \\
\hline & Coef. & Erro padrão & Prob. & Coef. & Erro padrão & Prob. & Coef. & Erro padrão & Prob. \\
\hline Intercepto & 1,9901 & 0,4136 & 0,0000 & 5,9749 & 0,1298 & 0,0000 & $-17,2014$ & 3,0028 & 0,0000 \\
\hline PS & 0,5131 & 0,0186 & 0,0000 & 0,3945 & 0,0032 & 0,0000 & 0,4777 & 0,0463 & 0,0000 \\
\hline PR & 0,0189 & 0,0385 & 0,6256 & 0,2748 & 0,0067 & 0,0000 & 0,1750 & 0,0266 & 0,0000 \\
\hline $\mathrm{AC}$ & $-0,1331$ & 0,0491 & 0,0097 & $-0,2381$ & 0,0088 & 0,0000 & 1,5346 & 0,2321 & 0,0000 \\
\hline CRC & 0,0648 & 0,0211 & 0,0037 & 0,0786 & 0,0040 & 0,0000 & $-0,0367$ & 0,0716 & 0,6109 \\
\hline \multirow[t]{4}{*}{ INT } & 0,1470 & 0,0129 & 0,0000 & 0,2742 & 0,0049 & 0,0000 & 0,2887 & 0,0425 & 0,0000 \\
\hline & 0,4941 & 0,0308 & 0,0000 & $-0,0295$ & 0,0036 & 0,0000 & 0,0763 & 0,0198 & 0,0004 \\
\hline & \multicolumn{3}{|c|}{$\mathrm{R}^{2}=0,9960 ; \mathrm{R}^{2}$ ajustado $=0,9949$} & \multicolumn{3}{|c|}{$\mathrm{R}^{2}=0,9975 ; \mathrm{R}^{2}$ ajustado $=0,9968$} & \multicolumn{3}{|c|}{$\mathrm{R}^{2}=0,9828 ; \mathrm{R}^{2}$ ajustado $=0,9780$} \\
\hline & \multicolumn{3}{|c|}{ F-stat. $=895,5 ;$ Prob. (F-stat. $)=0$} & \multicolumn{3}{|c|}{ F-stat. $=1473,7 ;$ Prob. $($ F-stat. $)=0$} & \multicolumn{3}{|c|}{ F-stat. $=205,0 ;$ Prob. $($ F-stat. $)=0$} \\
\hline
\end{tabular}

Nota: $\mathrm{PS}=$ preço de soja; $\mathrm{PR}=$ produtividade de soja; $\mathrm{AC}=$ área agrícola cultivada; $\mathrm{CRC}=$ crédito agrícola para custeio; $\mathrm{INT}=$ investimento no setor de transporte; $P T_{-1}=$ preço real de terra no período anterior.

Fonte: Resultados da pesquisa. 
Nos três modelos, os dados indicaram existência de correlação contemporânea, sendo necessário estimá-los pelo método SUR. Além disso, o teste de Hausman indicou que o modelo mais adequado para estimar os dados nos três casos seria o modelo de efeitos fixos.

Observa-se que os três modelos se ajustam bem ao preço da terra, com $\mathrm{R}^{2}$ ajustado igual a 0,9949 para o grupo de regiões de fronteira agrícola, 0,9968 para região de transição e 0,978 para o grupo de áreas desenvolvidas. A seguir é apresentada a discussão dos resultados relativa a cada variável.

A variável preço da soja obteve impacto positivo e relativamente elevado frente às demais variáveis sobre os preços das terras em todos os modelos estimados, representando a maior elasticidade nas regiões de fronteira e transição e a segunda principal variável na área desenvolvida. Assim, mantendo-se as demais variáveis constantes, um aumento de $1 \%$ do preço da soja levaria a um aumento de $0,51 \%$ no preço da terra na fronteira, de 0,39\% no preço da terra na área de transição e de $0,48 \%$ na região desenvolvida. Todos os coeficientes foram estatisticamente significativos a $1 \%$.

Isso indica que a renda obtida com a terra representada neste estudo pelo preço da soja -, conforme mostra a teoria, tem uma relação muito próxima com o preço deste fator de produção. $\mathrm{Na}$ prática, como abordou Zilli (2010), a negociação de terras tem sido, inclusive, indexada ao preço desta commodity.

Conforme algumas abordagens teóricas, o preço da terra é relacionado à renda que pode ser obtida com ela. Neste sentido, o preço da soja pode ser um fator importante para explicar o comportamento do mercado de terras em determinados momentos, tendo em vista que os preços de terra mencionados neste trabalho referem-se às principais regiões produtoras do grão. É notável que o movimento ascendente do preço da terra até 2004 coincide com a alta de preços de soja. A queda de preços em 2005 e 2006, recuperação em 2007 e movimento altista até 2009 também são observados nos dois mercados.
Nos grupos de regiões desenvolvidas e de transição a relação das duas variáveis é muito próxima. Na região de fronteira, por outro lado, a valorização da terra nos últimos anos supera a da soja, o que sugere que outros fatores, além da renda obtida com a sojicultura, têm contribuído para estimular a alta de preços deste fator. De modo geral, portanto, verifica-se que o preço da soja apresenta relação positiva com o preço da terra.

A variável produtividade agrícola foi estatisticamente significativa a $1 \%$ nos grupos de regiões de transição e desenvolvida e não significativa na região de fronteira. Nas duas primeiras regiões, a variável apresentou elasticidade positiva em relação ao preço da terra, condizendo com a teoria de que, aumentando-se a produção por área, seria possível obter renda maior e, com isso, valorização da terra. Além disso, um aumento da produtividade agrícola atrairia mais agricultores e indústrias para a região, valorizando a terra.

Alguns autores abordaram a produtividade como variável que influencia positivamente no preço da terra, dado o incremento na produção e, portanto, na renda do agricultor. Outros observaram, ainda, que a maior produtividade tende a diminuir a necessidade por terras para aumento da produção; assim, uma menor demanda por terras levaria a uma redução de seu preço.

Segundo Barros (2009), a produtividade teria uma relação inversa com o preço da terra enquanto houvesse condições de aumentá-la, ou seja, enquanto investimentos em tecnologia (fertilizantes, por exemplo) pudessem proporcionar aumento da produtividade e, com isso, obter maior renda por área cultivada. A partir do momento em que a produtividade se estabiliza quando ela chega a um nível próximo do máximo -, o aumento da produção passaria a depender da expansão da área de cultivo, valorizando a terra.

Deve ser ressaltado, ainda, o fato de que a produtividade no período analisado pode refletir não somente a capacidade de produção daquela região, considerando-se os fatores edafoclimáticos ou os investimentos realizados pelos produtores, mas também eventuais quebras de safra, 
que podem ocorrer em função de uma adversidade climática ou proliferação de algum tipo de doença nas plantas. Como exemplo, observa-se que, nos anos de 2004 e 2005, a produtividade nas áreas desenvolvida e de transição esteve em baixos níveis. O motivo, segundo o Cepea, foi excesso de chuva no norte de Mato Grosso, seca no sul de Mato Grosso do Sul, oeste do Paraná e norte do Paraná, e a incidência de ferrugem asiática no sudoeste de Goiás na safra 2003/04.

As elasticidades da área cultivada foram negativas nas regiões de fronteira agrícola $(-0,13)$ e de transição $(-0,24)$, e positiva - além de bastante elevada em relação às demais variáveis - na região desenvolvida $(1,53)$. Os três coeficientes foram significativos estatisticamente a $1 \%$. Esta variável reflete a demanda por terras para fins agrícolas (tanto lavouras permanentes quanto temporárias) e, de acordo com a teoria econômica, o seu impacto sobre o preço da terra depende da elasticidade da oferta deste fator.

De forma geral, muitos autores consideram a oferta de terra inelástica. Assim, uma expansão da área de cultivo - o que reflete um aumento da demanda por terra - proporcionaria a valorização deste fator. Entretanto, alguns estudos mostram que, especialmente em regiões menos ocupadas, como o Cerrado brasileiro, pode haver incremento da oferta de terras por meio da conversão de áreas de qualidade inferior ou de terras brutas em áreas de boa qualidade para a lavoura. Ou seja, a oferta de terras apresenta maior elasticidade, e um aumento da demanda (ou expansão de cultivo agrícola) poderia deslocar a curva de oferta para a direita, o que poderia proporcionar impacto menos expressivo ou mesmo negativo sobre o preço do fator.

Isso pode ser observado no trabalho de Rezende (2003), que argumenta que uma desvalorização da terra na década de 1990 pode ter sido provocada pela expansão da área de cultivo por meio da conversão de terras brutas ou de qualidade inferior em terra de boa qualidade. Ou seja, nestas regiões, a inovação tecnológica e expansão da área cultivada podem ter relação inversa com seu preço. Brandão, Rezende e Marques (2005) também estudaram a expansão no caso específico da área cultivada com soja. Segundo os autores, o rápido e intenso avanço da área de plantio do grão (especialmente na década de 1990 e, posteriormente, entre 2001 e 2004) ocorreu basicamente pela conversão de áreas de pastagens degradadas em área agrícola.

Observa-se que, na fronteira agrícola e na área de transição, o avanço da área de cultivo (que considera o total de lavouras temporárias e permanentes) é muito superior ao verificado na área desenvolvida, o que sugere que a oferta de terras para expansão de cultivo nessas duas regiões é maior. Entre 2002 e 2010, houve aumento da área cultivada de 58\% na fronteira agrícola, 55\% na área em fase de transição e de apenas $7 \%$ na região desenvolvida.

Assim, é possível que nas áreas menos desenvolvidas, além das regiões em fase de transição, a demanda por terras, representada pela área agrícola cultivada, tenha menor impacto sobre o preço deste fator ou mesmo negativo, à medida que a maior demanda gera maior conversão de terras brutas ou de pastagens em terras de cultivo. Do mesmo modo, em regiões de maior grau de ocupação agrícola (como é o caso do Sul e do Sudeste), a disponibilidade de terras é menor portanto, a oferta é praticamente inelástica. Neste sentido, uma elevação na demanda por área de cultivo poderia ter impacto maior (positivo) sobre o preço da terra.

O crédito agrícola para custeio apresentou coeficientes significativos estatisticamente a $1 \%$ nas áreas de fronteira agrícola e de transição, e não significativo na região desenvolvida. Nas duas primeiras regiões, as elasticidades foram relativamente baixas: 0,06 na fronteira e 0,08 na área de transição. Este resultado poderia explicar a menor necessidade de crédito agrícola nessa região pelo fato de apresentar maior concentração de grandes produtores agrícolas mais capitalizados, conforme observado por Miranda e Gomes (2011), além de se caracterizar por uma agricultura mais extensiva, utilizando menor investimento por área. Além disso, Rezende (1985) afirma que o crédito rural reduziria o risco 
da agricultura, tornando a terra uma opção mais "segura" para investimento.

Rezende (2001) comparou o crédito agrícola para custeio entre as regiões Sul, Sudeste e Centro-Oeste e verificou que, apesar da menor destinação do crédito ao Centro-Oeste entre 1969 e 1999, o fato de a agricultura local ser mais extensiva - e, portanto, apresentar menor custo por área -, diminuiria a necessidade de crédito de custeio por área em relação às demais regiões, nas quais a agricultura é mais intensiva no uso da terra.

Por outro lado, o Relatório da Safra 2010/11 do Cepea mostrou que o crédito de banco público pode ter pouca representatividade no total de recursos utilizados pelos produtores em algumas regiões, o que explicaria os coeficientes relativamente baixos.

"Muitos produtores não dispõem de crédito público por conta das prorrogações das dívidas passadas e não conseguem financiar as lavouras somente com os recursos próprios. Dessa maneira, eles recorrem às iniciativas privadas como as multinacionais, "tradings", as revendas e até mesmo recurso livre de bancos para financiar a safra, com juros nem sempre tão amistosos" (CEPEA, 2011).

O relatório do Cepea também mostra que a participação dos recursos provenientes de banco público é mais representativa na região Sul, devido ao fato de que, em geral, essa região apresenta propriedades relativamente menores se comparadas às demais regiões. Os autores explicam que como essa fonte de recursos tem um valor limite por Cadastro de Pessoa Física (CPF), em grandes propriedades o montante adquirido fica geralmente abaixo do necessário para custear a produção.

O relatório mostrou, ainda, que na região de Guarapuava (PR), por exemplo, 80\% dos recursos dos produtores provêm do banco a taxa de juros controlada, sendo o restante financiado por cooperativas locais; já em algumas regiões de Mato
Grosso, a maior parte dos recursos provém de traders, cooperativas e revendas (entre $25 \%$ e $60 \%$ do total de recursos), sendo que normalmente $30 \%$ do capital é próprio. Na região de Balsas (MA), por exemplo, $85 \%$ do recurso para custear a lavoura foi proveniente de traders, cooperativas e revendas, sendo o restante dos recursos proveniente de bancos públicos a juros controlados. Em Pedro Afonso (TO), 70\% dos recursos vieram também de empresas privadas; em Luís Eduardo Magalhães (BA) e Uruçuí (PI), esse percentual foi entre $30 \%$ e $40 \%$, sendo cerca de $30 \%$ dos recursos provenientes de bancos públicos a taxa de juros controlada. Nas regiões analisadas no Sul do País, por outro lado, o crédito proveniente de bancos públicos representa de $25 \%$ a $80 \%$ do total.

A variável investimento no setor de transportes apresentou elasticidade positiva e foi significativa estatisticamente nos três modelos estimados. Apesar de esta série de dados não representar o investimento específico de cada região, mostra que a evolução dos gastos neste setor teve correlação positiva com o preço da terra, podendo ser um indicativo de que os gastos com infraestrutura podem influenciar a demanda por terra e, consequentemente, seu preço.

Entretanto, os coeficientes foram maiores nas regiões mais ocupadas, ao contrário do esperado, tendo em vista que a fronteira agrícola necessita de maiores investimentos e, portanto, um avanço da infraestrutura deveria resultar em maior impacto sobre o preço da terra. Contudo, como esta variável representa os investimentos gerais no Brasil, a maior correlação com a região desenvolvida pode ter ocorrido em função dos maiores investimentos nesta região em relação às demais.

Silva, Jaime Junior e Martins (2009) abordam o gasto público com infraestrutura e mostram que um aumento neste gasto reduz o custo das empresas, o que, consequentemente, estimula o investimento, a produtividade e o crescimento da economia. Ocorre o fenômeno chamado de "crowding-in", definido por Pêgo Filho, Cândido Junior e Pereira (1999, citado por DOMINGUES, VIANA e OLIVEIRA, 2007), como o esforço de 
um país em se capacitar em infraestrutura, capital humano, tecnologia, entre outros, o que atrai investimentos privados. Neste sentido, melhores condições de infraestrutura levariam a uma maior demanda por terra e, como resultado, uma valorização deste fator.

Dadas as características das regiões menos ocupadas e com menor exploração econômica, um dos principais aspectos que as diferencia significativamente das áreas desenvolvidas é o nível de infraestrutura, tais como rodovias, ferrovias, quantidade de indústrias, armazéns, portos, entre outros (SICSÚ e LIMA, 2000).

Conforme mostraram Oliveira e Costa (1977), nos estados mais tradicionais no setor agropecuário o fator densidade viária parece ter atingido o ponto de saturação, enquanto em regiões menos ocupadas a rápida taxa de expansão dessa variável foi acompanhada de um aumento da demanda por terra. Em alguns casos, a relação chegou a ser negativa, uma vez que a expansão da infraestrutura pode ter ampliado a oferta de terra, sem que a demanda aumentasse na mesma proporção.

A variável preço da terra defasado em um período, que mostra como movimentos passados explicariam os próprios preços da terra, representando as expectativas dos agentes, apresentou coeficientes estatisticamente significativos a $1 \%$ em todos os modelos. A região de fronteira agrícola apresentou a maior elasticidade: um aumento de $1 \%$ no preço da terra no ano anterior acarretaria em aumento de $0,49 \%$ no preço da terra no ano corrente. Na região desenvolvida, o coeficiente foi bem menor, de 0,07 , e na região de transição a elasticidade foi negativa, de $-0,03$.

Neste contexto, nota-se que esta variável tem impacto muito maior na região de fronteira agrícola em relação às demais, o que estaria relacionado à escolha de investimentos de agentes (inclusive estrangeiros) nos últimos anos, devido ao potencial de crescimento em termos de produção, instalação de indústrias e infraestrutura e, portanto, de valorização da terra. Este fator especulativo pode ter sido responsável, inclusive, pelo maior crescimento médio anual do preço da terra na fronteira em relação às demais regiões.

No caso do coeficiente da região de transição, apesar de apresentar uma relação negativa, a elasticidade encontrada foi baixa $(-0,02)$, o que mostra que a expectativa não tem efeito relevante sobre o preço da terra nessa região.

Com o objetivo de avaliar o coeficiente geral de todas as regiões de estudo, foi estimado o modelo de dados em painel agrupado para os dados das áreas de fronteira agrícola, de transição e desenvolvida. Os resultados são apresentados na Tabela 2.

No modelo estimado para as três regiões agrupadas, foi identificada a existência de correlação contemporânea, pela matriz de correlação de resíduos, entretanto, o modelo foi estimado pelo método "Cross Section Weights" em função da quantidade de variáveis cross section. O teste de Hausman também indicou que o modelo mais

Tabela 2. Coeficientes estimados e níveis de significância para o modelo de demanda de terras conjuntamente nas regiões de fronteira agrícola, de transição e desenvolvida (2002 - 2010)

\begin{tabular}{cccc}
\hline Variável explicativa & Coeficiente & Erro padrão & Prob. \\
\hline Intercepto & 0,5369 & 1,4420 & 0,7101 \\
OS & 0,4520 & 0,0543 & 0,0000 \\
PR & 0,2238 & 0,0527 & 0,0000 \\
AC & 0,0331 & 0,1204 & 0,7836 \\
CRC & 0,1004 & 0,0510 & 0,0510 \\
INT & 0,0255 & 0,0225 & 0,2583 \\
PT $_{-1}$ & 0,3730 & 0,0526 & 0,0000 \\
\hline $\mathrm{R}^{2}=0,9690 ; \mathrm{R}^{2}$ ajustado $=0,9634$ & & \\
F-statistc $=173,3315 ;$ Prob. (F-statistic) $=0,0000$ & & \\
\hline
\end{tabular}

Fonte: Resultados da pesquisa. 
adequado para estimar os dados seria o modelo de efeitos fixos.

A análise do modelo de dados agregados leva em conta todas as unidades de cada região estimada anteriormente, aumentando o número de unidades de seção cruzada. De forma geral, as elasticidades estimadas para as variáveis independentes apresentaram comportamento semelhante ao observado nos modelos regionais, sendo um indicativo de que as estimações regionais são consistentes. As diferenças encontradas, portanto, podem estar relacionadas às diferenças existentes entre as regiões.

Analisando-se todas as regiões agrupadas, observa-se que, de forma geral, o preço da soja apresenta a maior elasticidade, e varia no mesmo sentido do preço da terra agrícola. Uma elevação de $1 \%$ do preço da soja leva a um incremento de $0,45 \%$ no preço da terra. O preço da terra no período anterior teve elevado impacto sobre o preço da terra no período corrente $(0,37)$. Neste caso, a elasticidade foi inferior à observada na região de fronteira, mas bastante superior à das demais regiões. A produtividade apresentou elasticidade de 0,22 , relativamente elevada se comparada às outras variáveis. Como observado nas análises regionais, esta variável foi positiva, mostrando que um aumento na produtividade geraria um aumento da renda e, portanto, valorizaria a terra. O crédito agrícola também apresentou elastici- dade positiva; porém, com pouco impacto sobre o preço da terra, assim como observado em cada região individualmente.

Os coeficientes estimados da área cultivada e do investimento no setor de transportes, contudo, não foram estatisticamente significativos. No caso da área cultivada, as diferenças existentes entre as regiões podem ter prejudicado a estimação do modelo em conjunto, fazendo com que a variável deixasse de ser significativa para determinar os preços da terra neste conjunto de dados. O mesmo motivo pode ter causado a perda da significância do intercepto neste modelo.

O modelo de dados em painel para os estados nos quais as regiões de estudo estão inseridas foi realizado com o intuito de abranger mais aspectos referentes à infraestrutura, tendo em vista que a variável utilizada no modelo com dados regionais abrange os investimentos realizados no Brasil todo, sem considerar a evolução local e, portanto, impactos mais realistas sobre o preço da terra. Assim, foi considerada a variável de capacidade de armazenamento de grãos, que não havia sido possível inserir nos modelos regionais. A Tabela 3 mostra os resultados obtidos nesta análise.

No modelo estimado para os estados onde se localizam as três regiões de estudo, foi identificada a existência de correlação contemporânea, pela matriz de correlação de resíduos; entretanto,

Tabela 3. Coeficientes estimados e níveis de significância para o modelo de demanda de terras para os estados da Bahia, Maranhão, Piauí, Tocantins, Goiás, Mato Grosso, Mato Grosso do Sul, Paraná e Rio Grande do Sul $(2002-2010)$.

\begin{tabular}{cccc}
\hline Variável explicativa & Coeficiente & Erro padrão & Prob. \\
\hline Intercepto & 2,2270 & 1,7950 & 0,2199 \\
OS & 0,3768 & 0,0529 & 0,0000 \\
PR & 0,0810 & 0,0411 & 0,0537 \\
AC & 0,0383 & 0,1141 & 0,7380 \\
CRC & 0,0195 & 0,0500 & 0,6967 \\
ARM & 0,0779 & 0,0353 & 0,0316 \\
INT & 0,0573 & 0,0206 & 0,0076 \\
PT 1 & 0,2636 & 0,0779 & 0,0013 \\
\hline$R^{2}=0,9690 ; R^{2}$ ajustado $=0,9634$ & & \\
F-statistc $=173,3315 ;$ Prob. (F-statistic) $=0,0000$ & & \\
\hline
\end{tabular}

Fonte: Resultados da pesquisa. 
o modelo também foi estimado pelo método "Cross Section Weights" em função da quantidade de variáveis cross section. O teste de Hausman também indicou que o modelo mais adequado para estimar os dados seria o modelo de efeitos fixos.

Neste modelo, a evolução da capacidade de armazenamento de grãos por estado, que representa também a infraestrutura, obteve elasticidade de 0,08 , pouco superior ao coeficiente do investimento em transporte de 0,057 . Isso mostra que o avanço da infraestrutura tem relação positiva com o preço da terra, porém, não representa grande impacto neste conjunto de dados. Aparentemente, a formação de preços deve-se, sobretudo, à renda e às expectativas.

Novamente, o preço da soja foi a variável de maior impacto sobre o preço da terra $(0,38)$, representando a importância da renda gerada por este fator neste mercado, seguido do preço de terra defasado em um período $(0,26)$. A produtividade também apresentou elasticidade positiva; porém, relativamente baixa em relação ao preço da terra $(0,08)$.

Já o intercepto, a área cultivada e o crédito agrícola não obtiveram resultados significativos estatisticamente, provavelmente em função da grande variação desses dados entre os estados.

\section{Conclusões}

Com base nos diversos estudos acerca do mercado de terras, o presente trabalho analisou as diferenças dos impactos de algumas variáveis sobre o preço da terra em três regiões brasileiras produtoras de soja. A análise empírica, realizada pelo método de dados em painel, mostrou que o preço de soja, que representa a renda obtida com a terra, foi bastante relevante em todos os modelos estimados, tanto para cada região como para os dados agrupados e dados estaduais. Isso mostra que, conforme verificado em diversos estudos sobre este mercado, o preço da terra está fortemente relacionado à renda que se pode obter com este fator.
O fator relacionado às expectativas, representado pela variável do preço real da terra defasado em um período, apresentou elevada elasticidade (positiva) na região de fronteira agrícola, enquanto na região desenvolvida este coeficiente foi relativamente baixo. Isso confirma a hipótese de que um maior potencial de crescimento das áreas menos exploradas em termos de infraestrutura, instalação de indústrias etc., atrai a demanda por terras para fins especulativos, por parte inclusive de grupos investidores nos últimos anos. A variável analisada também foi significativa estatisticamente e positiva quando analisada no conjunto de dados regionais e estaduais, mostrando-se importante na determinação dos preços da terra.

Observou-se, também, que a grande diferença da disponibilidade de terras existente nas três regiões interfere na determinação dos preços deste fator. A partir da análise da área agrícola cultivada (que representa a demanda por terras para fins agrícolas), foi possível observar elasticidades negativas nas regiões de fronteira e de transição, enquanto na região desenvolvida o coeficiente foi positivo, apresentando coeficiente de elasticidade mais elevado em relação às demais variáveis. Isso pode ser explicado pelo fato de que o impacto do aumento da demanda por terras para cultivo sobre o preço deste fator dependerá da elasticidade da oferta de terras em cada região. Tendo a região desenvolvida uma oferta praticamente inelástica deste fator produtivo, a elevação da demanda implicará em aumento significativo do preço da terra. Por outro lado, nas regiões menos ocupadas, uma maior demanda pode levar ao aumento da conversão de terras brutas ou de pastagens em terras produtivas, elevando o estoque deste fator (deslocando a curva de oferta de terras para a direita), o que impactaria negativamente no preço da terra.

O crédito agrícola também foi uma variável importante para explicar o preço da terra. Os coeficientes relativamente baixos se comparados às demais variáveis pode ser explicado pela baixa representatividade dessa fonte de recursos para custear a produção em relação às demais, como 
as empresas privadas, especialmente no CentroOeste e na fronteira agrícola. Na análise conjunta dos dados regionais, esta variável também apresentou impacto positivo e estatisticamente significativo. Já nos dados estaduais, o crédito agrícola não apresentou resultado significativo estatisticamente.

Neste estudo, a variável produtividade apresentou relação positiva com os preços da terra e estatisticamente significativa nas regiões de transição e desenvolvida. Isso mostrou que um aumento da produtividade levaria a um acréscimo da renda obtida com a terra, além de atrair mais produtores e indústrias, elevando a demanda por este fator e valorizando a terra.

O investimento no setor de transportes, variável que representa a evolução da infraestrutura, mostrou-se positiva em todos os modelos estimados. Entretanto, por se tratar de um investimento geral no Brasil, não foi possível captar as reais diferenças entre as regiões analisadas. Ao contrário do esperado, a elasticidade observada na região de fronteira foi inferior à das demais regiões. Isso contraria a hipótese de que, nessa região, que tem menor nível de infraestrutura, um avanço neste setor teria impacto maior no preço da terra. Outra variável relacionada à infraestrutura - capacidade de armazenamento - foi analisada no modelo de dados estaduais. A elasticidade obtida também foi positiva e significativa estatisticamente, mostrando-se importante para determinar o preço da terra; o impacto sobre o preço do fator, porém, foi relativamente baixo se comparado às demais variáveis explicativas.

Uma das limitações deste trabalho refere-se à dificuldade de obtenção de algumas informações específicas para os municípios, como dados relacionados aos custos de produção e variáveis sobre a evolução de infraestrutura. Para a realização de novas pesquisas, sugere-se analisar a evolução da disponibilidade de terras agricultáveis em cada região (disponível apenas nos Censos Agropecuários, do IBGE), e dados referentes às propriedades rurais negociadas (o que exigiria bastante tempo, dada a grande quantidade de municípios estudados). Estas informações pro- porcionariam um estudo mais aprofundado sobre a oferta e demanda existente no mercado de terras. A continuidade desta análise, bem como sua ampliação, também deve ser feita para avaliar os efeitos de algumas variáveis a partir de 2010 (especialmente na fronteira agrícola), quando foi restringida a compra de terras por estrangeiros no Brasil.

Este trabalho analisou o mercado de terras de forma mais específica, abrangendo diferenças de algumas regiões brasileiras. A importância desta análise deve-se ao fato de que, além de a terra ser um fator bastante heterogêneo, o Brasil tem regiões muito distintas em termos de ocupação, infraestrutura e desenvolvimento. Neste sentido, conclui-se que as características regionais são fundamentais para compreender o comportamento do mercado de terras, uma vez que diversos fatores que determinam o preço da terra têm impactos diferentes em cada região.

\section{Referências bibliográficas}

AGRAFNP - Consultoria \& Comercio, AGRIANUAL 2004. Anuário da agricultura brasileira. São Paulo; IFNP, 2004, 496p.

AGRAFNP - Consultoria \& Comercio, AGRIANUAL 2005. Anuário da agricultura brasileira. São Paulo; IFNP, 2005, 520p.

AGRAFNP - Consultoria \& Comercio, AGRIANUAL 2006. Anuário da agricultura brasileira. São Paulo; IFNP, 2006, 504p.

AGRAFNP - Consultoria \& Comercio, AGRIANUAL 2007. Anuário da agricultura brasileira. São Paulo; IFNP, 2007, 516p.

AGRAFNP - Consultoria \& Comercio, AGRIANUAL 2008. Anuário da agricultura brasileira. São Paulo; IFNP, 2008, 502p.

AGRAFNP - Consultoria \& Comercio, AGRIANUAL 2009. Anuário da agricultura brasileira. São Paulo; IFNP, 2009, 497p.

AGRAFNP - Consultoria \& Comercio, AGRIANUAL 2010. Anuário da agricultura brasileira. São Paulo; IFNP, 2010, 520p.

AGRAFNP - Consultoria \& Comercio, AGRIANUAL 2011. Anuário da agricultura brasileira. São Paulo; IFNP, 2011, 482p. 
BANCO CENTRAL DO BRASIL - BACEN. Anuário Estatístico do Crédito Rural. Disponível em: < http:// www.bcb.gov.br/?RED2-RELRURAL $>$. Acesso em: 02 de fevereiro de 2011.

BARROS, G. S. C. O quebra-cabeça do preço da terra no Brasil. CEPEA, mimeo, 2009.

BRANDÃO, A. S. P. Mercado de terra e estrutura fundiária. In: Os principais problemas da agricultura brasileira: análise e sugestões. Rio de Janeiro: IPEA/ INPES, 1988. p. 139-179.

BRANDÃO, A. S. P., REZENDE, G. C. e MARQUES, R. W. C. Crescimento agrícola no período 1999-2004, explosão da área plantada com soja e meio ambiente no Brasil. Rio de Janeiro: Instituto de Pesquisa Econômica Aplicada, 2005. Disponível em: < http://cdi.mecon.gov.ar/biblio/ doc/ipea/td/1062.pdf > . Acesso em 20 fev. 2012.

BRASIL. Ministério dos Transportes. Série histórica de investimentos no setor de transportes. Disponível em: <http://www.transportes.gov.br/public/arquivo/ arq1323797748.pdf>. Acesso em: 03 dez. 2011.

CASTRO, A.C. e FONSECA, M. G. D. O potencial do agribusiness na fronteira. Revista de Economia Política, São Paulo: Centro de Economia Política, v. 14, n. 1, p. 63-84, jan./mar. 1994.

CENTRO DE ESTUDOS AVANÇADOS EM ECONOMIA APLICADA. Relatório da safra 2010/11: Grãos e Fibras. Piracicaba: Universidade de São Paulo, Escola Superior de Agricultura "Luiz De Queiroz" ESALQ, Departamento de Economia, Administração e Sociologia, Centro de Estudos Avançados em Economia Aplicada. Mimeo, 2011. 121p. Relatório técnico apresentado à Confederação da Agricultura e Pecuária-CNA.

DUARTE, P. C., LAMOUNIER, W.M. e TAKAMATSU, R.T. Modelos econométricos para dados em painel: aspectos teóricos e exemplos de aplicação à pesquisa em contabilidade e finanças. In: CONGRESSO USP DE INICIAÇÃO CIENTÍFICA EM CONTABILIDADE, 4, 2007, São Paulo. Anais... São Paulo: FEA/USP, 2007.

GUJARATI, D. N. e PORTER, D. C. Econometria básica. 5aㅡ. ed. Rio de Janeiro: AMGH Editora Ltda., 2011.

EGLER, C. A. G. Preço da terra, taxa de juro e acumulação financeira no Brasil. Revista de Economia Politica, São Paulo, v.5, n.1, p.112-135, jan./mar. 1985.

HSIAO, C. Analysis of panel data. Cambridge: University of Cambridge, 2003. Disponível em: < http://bilder. buecher.de/zusatz/22/22465/22465755_lese_1.pdf >. Acesso em: 20 dez. 2011.
HERDT, R. W. e COCHRANE, W. W. Farm land prices and farm technological advance. Journal of farm economics, v. 48, n. 2, p. 243-263, 1966.

INSTITUTO BRASILEIRO DE GEOGRAFIA E ESTATÍSTICA. Pesquisa de Produção Agrícola Municipal. Disponível em: <http://www.sidra.ibge.gov.br/bda/ acervo/acervo2.asp $? \mathrm{e}=\mathrm{v} \& \mathrm{p}=\mathrm{PA} \& \mathrm{z}=\mathrm{t} \& \mathrm{o}=11>$. Acesso em: 20 fev.2011.

INSTITUTO DE PESQUISA ECONÔMICA APLICADA. IGP-DI - geral: índice ago/1994=100. Disponível em: $<$ http://www.ipeadata.gov.br/>. Acesso em: 20 jul. 2011.

JUDGE, G.G. et al. Introduction to the theory and practice of econometrics. 2. ed. New York: John Wiley, 1988. 1024 p.

LEVIN, A., LIN, C. F. e CHU, C. S. J. Unit root tests in panel data: asymptotic and finite-sample properties. Journal of Econometrics, n. 108, p. 1-24, 2002.

MIRANDA, R. S. e GOMES, R. A. Dinâmicas agrárias e conflitos socioambientais no sul do Maranhão. In: XXVIII CONGRESSO INTERNACIONAL DA ALAS, 28, 2011, Recife. Anais... Recife: UFPE, 2011.

OLIVEIRA, J. T. e COSTA, I. D. N. Evolução recente do preço da terra no Brasil: 1966 - 1974. Revista de Economia e Sociologia Rural, Vitória, v.15, n. 3, p. 269-276, 1977.

PÊGO FILHO, B., CÂNDIDO JUNIOR, J. O. e PEREIRA, F. Investimentos e financiamento da infraestrutura no Brasil: 1990/2002. Brasília: IPEA, 1999. Texto para Discussão no 680. Apud DOMINGUES, E. P.; VIANA, F. D. F; OLIVEIRA, E. C. Investimentos em infra-estrutura no Nordeste: projeções de impacto e perspectivas de desenvolvimento. Belo Horizonte: UFMG, 2007. Texto para Discussão n. 319.

PINHEIRO, F. A. A renda e o preço da terra: uma contribuição à análise da questão agrária brasileira. 1980. 277p. Tese (Livre docência) - Escola Superior de Agricultura "Luiz de Queiroz", Universidade de São Paulo, Piracicaba, 1980.

PRADO, E. F. S. Estrutura tecnológica e desenvolvimento regional. São Paulo: IPE/USP. Ensaios Econômicos, n. 10. Apud CASTRO, A. C.; FONSECA, M. G. D.. O potencial do agribusiness na fronteira. Revista de Economia Política, São Paulo, v. 14, n. 1 (53), jan./mar. 1994.

RAHAL, C. S. A evolução dos preços da terra no estado de São Paulo: análise de seus determinantes. 2003. 185p. Dissertação (Mestrado) - Escola Superior de Agricultura "Luiz de Queiroz", Universidade de São Paulo, Piracicaba, 2003. 
REYDON, B. P. e PLATA, L. A. Evolução recente do preço da terra rural no Brasil e os impactos do Programa da Cédula da Terra. Disponível em: <http://www.nead.gov.br/home/ estudoseprojetos2.htm >. Acesso em: $10 \mathrm{dez} .2011$.

REZENDE, G. C. Política Agrícola, preço da terra e estrutura agrária. Revista de Economia Rural. Brasília, v. 20, n. 1, p. 73-100, 1982.

REZENDE, G. C.. A agricultura e a reforma do crédito rural. Revista Brasileira de Economia, Rio de Janeiro, v. 39, n. 2, p. 185-206, 1985.

REZENDE, G. C. Política de crédito rural e expansão agrícola doscerrados.In:GASQUES,J.G.eCONCEIÇÃO, J. C. P. R. (Org.). Transformações da Agricultura e Políticas Públicas. Brasília: IPEA, 2001, p. 214-242.

REZENDE, G. C. Ocupação Agrícola e Estrutura Agrária no Cerrado: o papel do preço da terra, dos recursos naturais e da tecnologia. 2003. Disponível em: <http:// www22.sede.embrapa.br/unidades/uc/sge/ocupacao_ agraria.pdf.> Acesso em: 10 fev. 2011.
SAYAD, J. Preço da terra e mercados financeiros. Pesquisa e Planejamento Econômico, Rio de Janeiro, v. 7, n.3, p. 623-662, dez. 1977.

SILVA, G. J. C., JAYME JUNIOR., F. G. e MARTINS, R. S. Gasto público com infraestrutura de transporte e crescimento: uma análise para os estados brasileiros (1986-2003). CEPEAD/UFMG. Revista Economia \& Tecnologia, Curitiba, v. 16, ano 5, jan./mar. 2009.

SICSÚ, A. B. e LIMA, J. P. R.. Fronteiras agrícolas no Brasil: a lógica de sua ocupação recente. Nova Economia, Belo Horizonte, v. 10, n. 1, jul. 2000.

WOOLDRIDGE, J. M. Econometric Analysis of Cross Section and Panel Data. Cambridge: MIT Press, 2001.

ZILLI, J. B. Variação das propriedades rurais em Carzinho/ RS e Cascavel/PR: uma análise das opções reais. 2010. 148p. Tese (Doutorado) - Escola Superior de Agricultura "Luiz de Queiroz", Universidade de São Paulo, Piracicaba, 2010. 